\title{
The Technique and Ecology Surrounding Moray Fishing: A Case Study of Moray Trap Fishing on Mactan Island, Philippines
}

\author{
Takashi Tsuji, National Museum of Ethnology (Minpaku), Japan
}

\section{Introduction}

The Republic of the Philippines is made up of over 7,100 islands and archipelagos of all sizes. The Visayas region of islands is centrally located south of Luzon and north of Mindanao, and is surrounded on the east and west by the Panay and Negros islands, and the Samar and Leyte islands, respectively. The residents of the Visayas region fish masterfully, applying fishing methods and tools that are suitable to this inland sea ecology (Balogo 1996; Calderon-Hayhow et al. 1994; Green et al. 2004; Rau 1979; Schoppe et al. 1998; Tawa 1981, 2006; Tsuji 2007a; Yano 1994; Yano and Kobayashi 1994; Zayas 1994, 2004).

The research findings reported in this paper focus on one of the fishing tools and fishing methods utilised in the Visayas inland sea area, the bamboo fishing trap, which is used primarily to trap moray eels.

Fish traps are widely used in various locations across the globe including the target region of this study. Inhabitants of Mactan Island, Cebu, use bamboo traps extensively. Trap fishing of morays at shallow depths is the primary method used in this region, especially by the offshore fishing businesses off the coast of Cebu (Green et al. 2004).

Previous research on fish traps and moray trap fishing activities in the Philippines is limited. As for the traps themselves, Balogo (1996) cited the Gimbaleños trap as an example of a bamboo made trap used as a fishing tool. However, Balogo only provided a name for the trap and a brief description. Calderon-Hayhow et al. (1994) and Umali (1950) published illustrations of fishing tools and fishing methods from the eastern region of Negros and the whole of the Philippines, but again, only included brief descriptions. Cadelinna et al. (1986) studied traps used on Siquijor Island from an archeological material-culture perspective, but document the collected information without offering any analytical discussion. From this body of research, we can determine the variety of traps in each region and their distribution, but we cannot know the technology used to 
create the traps, usage techniques, the environment in which they were utilised, or their structural and functional attributes from a fishing ecology perspective. In contrast, Rau (1979) studied the methods of small fishing businesses in the areas surrounding Cebu from an ecological perspective, reporting the names of the fishing methods, the structure of the tools, the targeted fish and fishing seasons, the environment in which the traps are used, and the productivity of these fishing methods. Rau's research is therefore valuable as a baseline reference point.

A rough understanding of moray fishing can be gleaned from the preceding studies and newspaper articles (Garcia 2003), but to date, ethnographic research focusing on moray fishing in the Philippines has not been conducted. Given this backdrop, in 2005, the author conducted a preliminary ecological anthropological study of moray trap fishing on Mactan Island, Cebu. This study describes the actual construction of the moray trap and an analysis of the time periods during which the trap is used in relation to tide and weather conditions at the trapping locations (Tsuji 2007b). Due to scheduling constraints, the author was only able to do an on-board study once, making it impossible to conduct a sufficient weight study necessary for productivity discussions. In order to compensate for this deficiency, another study was conducted in 2008. This report documents the information from that study, intermingling data from 2005 as needed.

The primary objectives of this report are 1) to disclose the true condition of moray fishing in Cordova on Mactan Island in Cebu, Philippines, and 2) to document and discuss the technique and ecology of moray trap fishing including a) the structure of the trap, b) the times and usage of the trapping grounds, and c) the effectiveness of the trap. An additional goal of this document is to clarify how the moray trap fishing technique reflects the ecological environment of the region.

The supplemental study for this report was carried out from 29 June through 25 August 2005, while the on-board study was conducted on 31 July. A second study was conducted from 28 May through 31 May 2008. The primary research methods were individual tracing ${ }^{1}$ using participant observation and a Global Positioning System receiver, and weight studies using a spring scale and interviews. Written surveys were incorporated as well.

\section{Overview of the Investigated Site}

Mactan Island is located on the east side of Cebu Island, in Cebu Province (Figure 1). There is an international airport and a Mactan Export Processing Zone (MEPZ) along with many beach resorts. Mactan Island has a relatively dry climate, receiving a mean rainfall value of approximately $100 \mathrm{~mm}$ of precipitation monthly from February through May. There is a marked rainy season from June to January. The average precipitation rate and temperature per year is $1,547.1 \mathrm{~mm}$ and $28.1^{\circ} \mathrm{C}$, respectively (Cebu Pagasa Complex 2005).

This study was conducted in Sitio Kawayanan, the Kawayanan borough, within the Barangay Poblacion District in the centre of the Municipality of Cordova on the southeast side of Mactan Island. Cordova is located approximately $22 \mathrm{~km}$ from Cebu City, and in 2007, it had a population of 45,713 . The residents use Cebuano as their common language and $95 \%$ are Christian (Roman Catholic) by faith. The service industry and manufacturing companies employ a majority of the workforce while approximately $20 \%$ of the households have a family member working at the MEPZ. Thirteen percent of households are in the fishing business (Ator 2007;

1 The Individual Tracing Method is used primarily as a means of capturing the activities and allotment of time in everyday living in the fields of ecological anthropology and human ecology. An individual surveyor constantly moves about with the target individual being surveyed. The advantage of this method is that the researcher observes the surveyed subject's activities in detail. That data from multiple surveys cannot be collected has been pointed out as a disadvantage to this method (Suda 1994). The author would like to acknowledge that the data from the individual tracing method used in this report (on-board survey) is a record of only two moray trap fishermen. This report discusses in detail an aspect of the state of moray trap fishing in Cordova on Mactan Island. However, providing a comprehensive picture of this issue is beyond the scope of this study, and is a topic for future research. 
Municipality of Cordova 2004; San Carlos Publications et al. 2004). Approximately 300 people living in 53 households reside in the Kawayanan borough and have easy access to the ocean and public markets. Fourteen households acquire their primary income from the MEPZ, twelve of whom have a member working as a driver for a trisikad (a bicycle with a sidecar used for public transportation). There are eleven households in the fishing business, three of which are currently engaged in harvesting moray eels with fish-traps (mamakasi). Besides this method of fishing, people also engage in practices aimed at gill netting (manukut) of mottled spinefoot danggit; shellfish diving (manaon); trap fishing (maneming) for kasag (swimming crab) or ibis (cardinal fish family); night-fishing for tama (Octopus oliveri) and general gleaning (manginhas), as well as catching peanut worms salpo (Sipunculus robustus) and wedge sea hares dunsol (Dolabella auricularia) (Tsuji 2007a).

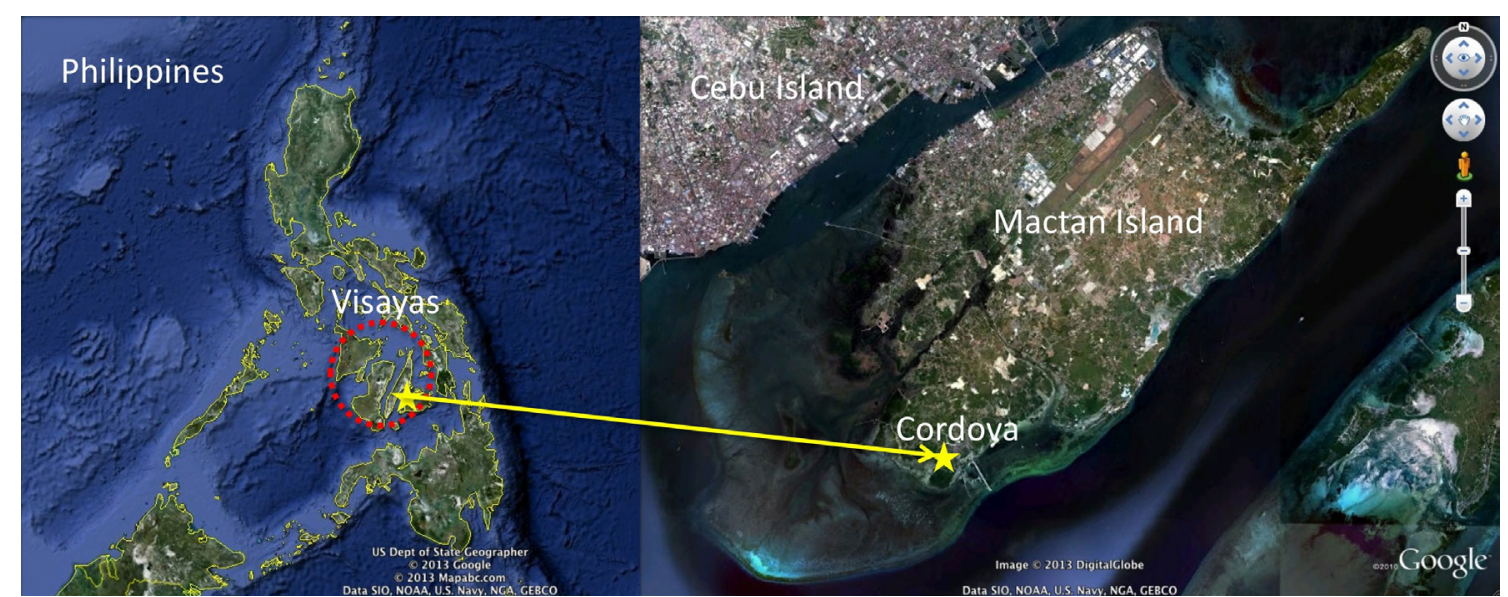

Figure 1. The location of the field survey.

Source: Drawn by the author, based on a Google Map.

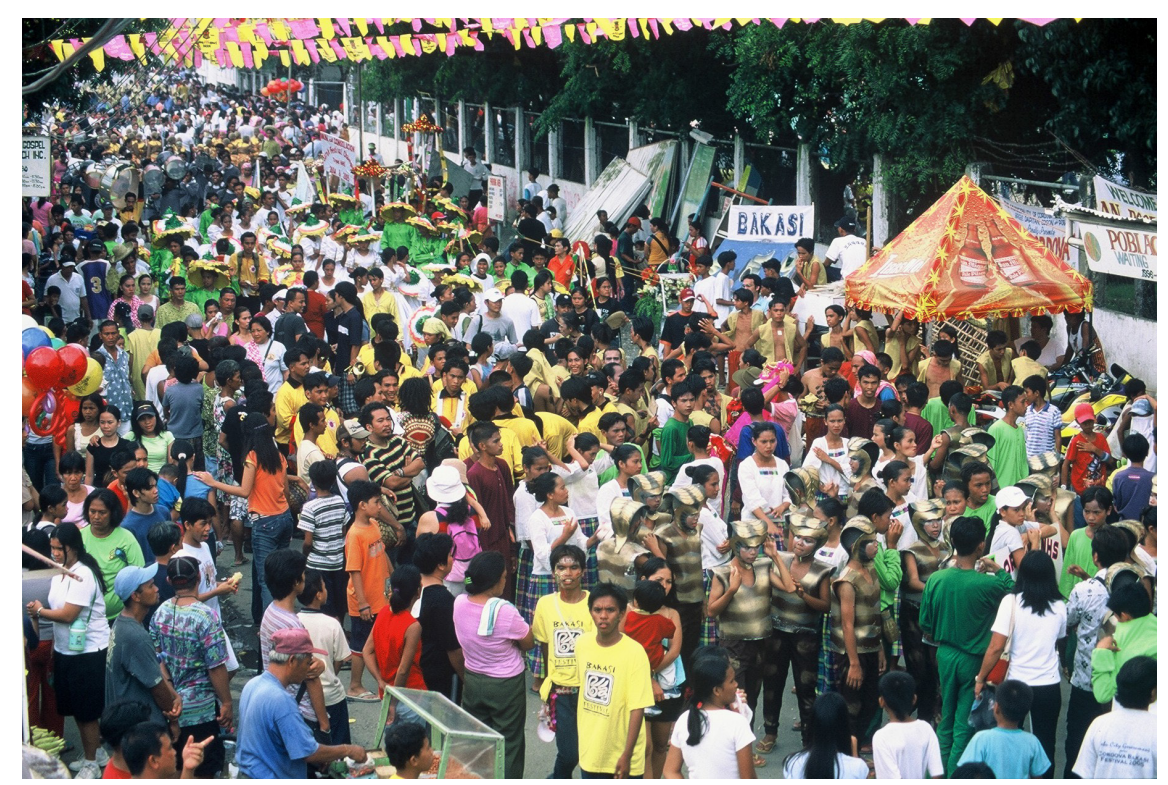

Figure 2. The Moray Festival.

Source: Photo by the author.

Thirty-four percent of all households in Cordova are in the fishing business and $43 \%$ have a member who is employed full-time in fish harvesting (Municipality of Cordova 2004). These 
statistics demonstrate the presence of an intimate link between the people of Cordova and their marine environment. The Dinagat Festival (Sea Festival), which was held in Cordova every August from 1999 through 2004, arose from this close relationship and provided a means of promoting tourism. In 2005, leveraging their primary local marine resource with the aim not only of promoting tourism, but also supplementing the fishing household livelihood and income, the festival was changed to the Bakasi Festival (Moray Festival). It is now a focus of economic stimulus for the region (Figure 2).

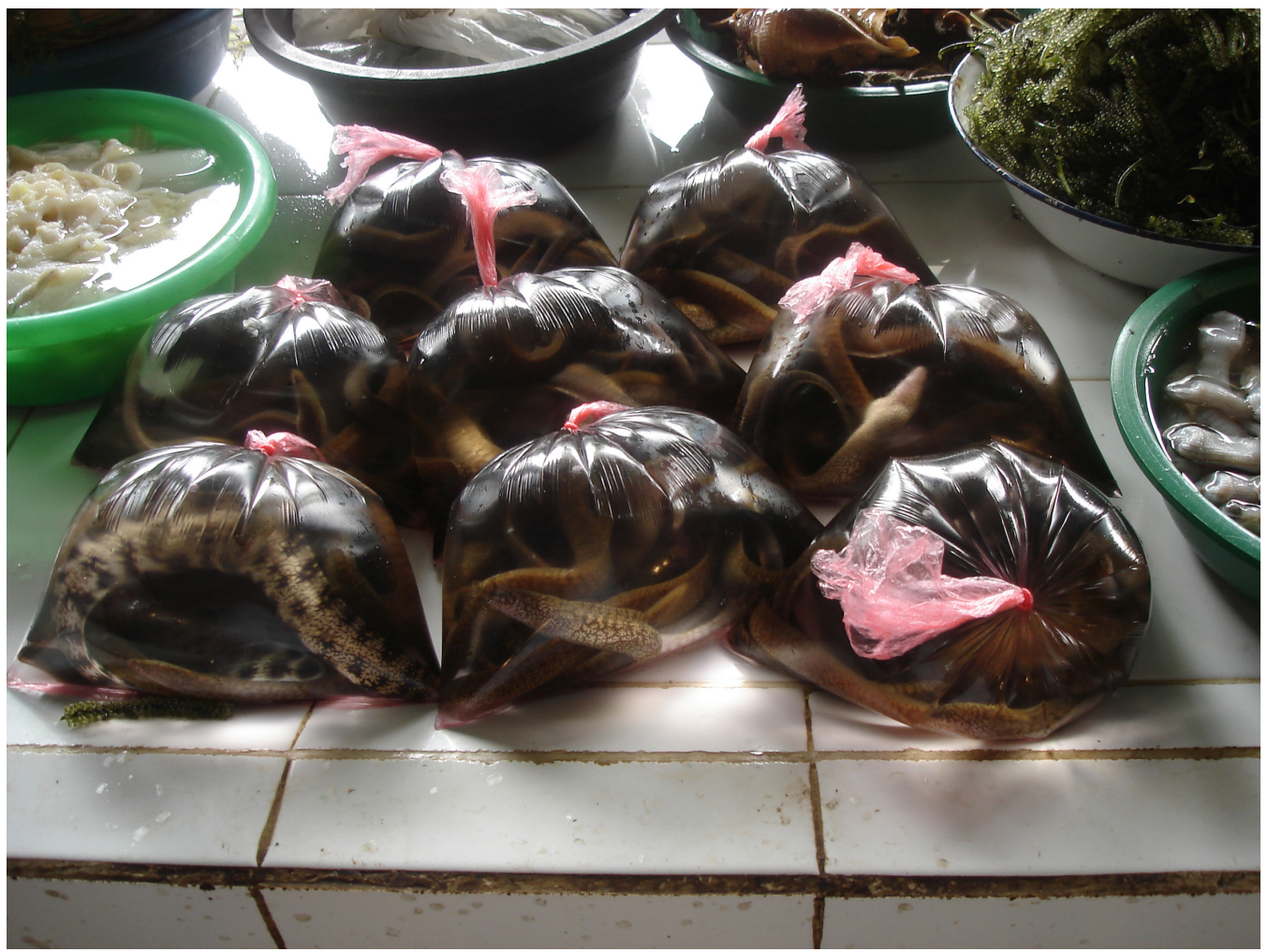

Figure 3. Live Morays at the market.

Source: Photo by the author.

\section{Moray and Moray Traps}

\section{Moray (bakasi)}

The target of moray trap fishing is a moray eel called bakasi. This is a relatively small size species of moray eel (unidentified) of about $10-25 \mathrm{~cm}$. Mixed into the catch are also snowflake moray (Echidna nebulo) halawig, and ubod (not confirmed), but they are considered ancillary prey taxa.

The hardiness of these morays allows the fishermen to hold them in a container for up to four days before taking them to market. This enables fisherman to harvest a sufficient number before taking them to be sold. Morays are sold on the open market in Cordova, but middlemen transport live morays by truck to locations such as Cebu's largest market, Carbon Market, and presumably onto Mabolo in Cebu City as well as Tabunok, which is located 9km west of the city centre (Garcia 2003).

Fishermen sell the morays to middlemen for 50 to 70 pesos per caltex. About 15 living morays are placed in a sack and lined up for sale at the market (Figure 3). One sack is sold for about 20 pesos. They are sold with the smaller snowflake moray mixed in together. Some morays are processed, dried, and sold at the market. Some people say that the moray eels are harvested and sold live because they are fresher that way, but morays are also considered an aphrodisiac, so it can 
be inferred that there is a significant marketing advantage to delivering the conduit to improved virility while it is still alive. These smaller morays are rich in gelatinous fatty tissue and are mainly prepared in soups (tinola), or fried together with black beans and spices (linarang) or grilled over open coals (Sollano 2005). The larger morays are not preferred for consumption because their flesh is tougher and they contain many bones.

\section{Moray traps (bantak)}

The moray trap (bantak) (Figure 4) discussed in this study is woven with bamboo (kawayan). The height of the basket trap is approximately $23 \mathrm{~cm}$; it is $32 \mathrm{~cm}$ around at its widest point, and $16.5 \mathrm{~cm}$ at the thinnest point of its body, and weighs about 100g. Given its name, it is believed that in the Kawayanan borough (Sitio Kawayanan), there used to be many bamboo groves, but they are hard to find today. Baskets are made from either bamboo that is found nearby or purchased.

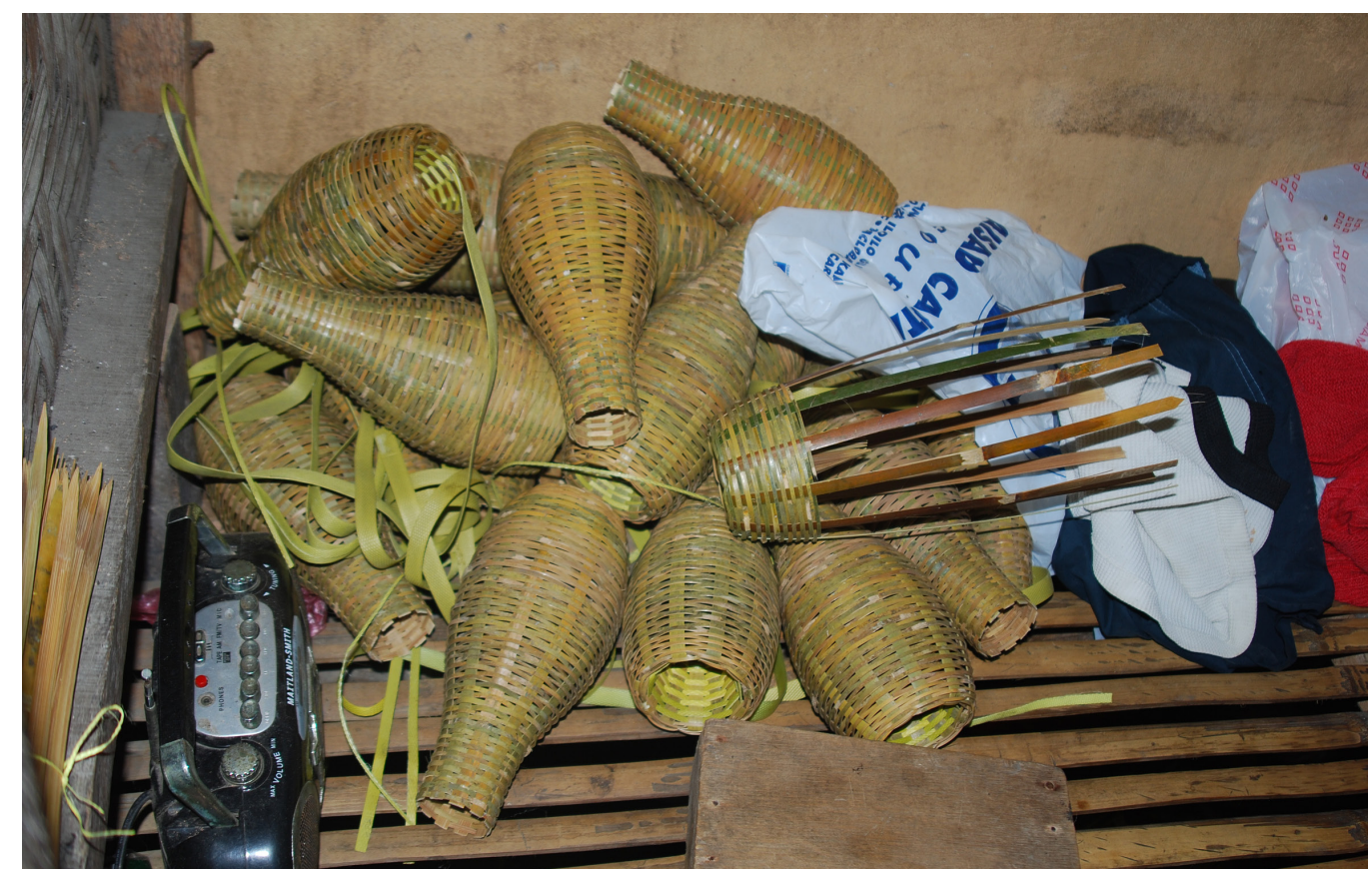

Figure 4. Moray traps (bantak).

Source: Photo by the author.

I was unable to confirm the exact type of bamboo, but a green bamboo about $2 \mathrm{~m}$ in length and $40 \mathrm{~cm}$ in circumference can be purchased for 45 pesos ( 1 peso was approximately 0.02 USD at the time in 2008). The bamboo is sliced into thin strips with a knife or hatchet. Eleven strips (approx. $40 \mathrm{~cm}$ long, $7 \mathrm{~mm}-1 \mathrm{~cm}$ wide, $1 \mathrm{~mm}$ thick, with both ends sharpened to a point and one end used as a fold-back) are used for the vertical frame. Six strips $(1.5 \mathrm{~m}$ long, $3.5-5 \mathrm{~mm}$ wide, and $1 \mathrm{~mm}$ thick) are used for the horizontal frame and together, they form a jar-like shaped weave leaving no openings. On the bottom of the jar portion, strips are left folded back to prevent a moray from exiting. The opening of the jar is where the moray enters the trap and where the bait is inserted. In order to reinforce yet preserve suppleness, $2 \mathrm{~mm}$ wide polypropylene bands are woven into both portions of the trap.

It is said that in the past, bamboo strips were used to reinforce the traps, but after the year 2000, polypropylene bands began to be used. It is reported that rattan had been used as reinforcement on Siquijor Island in the 1980s (Cadeliña et al. 1986). A stopper for the trap is made by cutting out a portion of used rubber beach slippers (whose strap may be broken) and inserted into the 
mouth of the trap. Until around 1990, wood was used for the stopper, while fishing nets or rags were used on eastern Negros Island (Calderon-Hayhow et al. 1994). Somewhat centrally located between the body and the mouth of the trap are loops made of polypropylene bands. The trap is secured at the fishing ground by pinching these loops with a forked bamboo stick to keep the trap from being washed away by the waves. In Cordova, these forked bamboo sticks are used to secure the trap (Rau 1979), but it is reported that on Siquijor Island, rocks are tied to the trap to secure it to fishing spots (Cadeliña et al. 1986).

It is a man's job to weave bamboo traps. An aged pair of brothers who are veterans of weaving these bamboo traps live in the Kawayanan borough. The elder brother weaves traps for morays (bantak) while the younger brother weaves square traps (teming). Kasag (swimming crab) or ibis (cardinal fish family) are caught for bait of maneming-fishing. These brothers also engage in fishing activities using these types of traps. They learned the art of making these traps from their father and have been weaving them since they were young. They can weave 1 trap in about 40 minutes. A bantak sells for about 20 pesos and a teming for about 25 pesos. They weave and sell the traps once an order is placed. In general, a moray trap will last about 5 months.

In addition to bamboo traps, buhi-an containers are also woven to hold live morays. Buhi means (life) in the Cebuano language and with the suffix "-an" means a container to allow them to remain living. Besides strapping this container to the cross arm of the boat along its side to keep morays alive while harvesting, it is also used as the holding tank until they are taken to market. The size of this woven buhi-an differs according to the size of the boat or the need, but the largest ones are as long as $155 \mathrm{~cm}$ long and $94 \mathrm{~cm}$ in circumference at their widest point. Both ends are reinforced with bamboo tubes in order to maintain their strength. The body of the buhi-an is woven with bamboo in a similar fashion to the traps. Polypropylene bands are used in spots that easily fall apart. In the middle section of the buhi-an, there is an opening that is approximately $21 \mathrm{~cm}$ long and $8 \mathrm{~cm}$ wide using strips of wooden or rubber sandals, which is created for inserting and retrieving the moray eel. Worn out rubber sandals are used for the lid of this opening and are held down like a stopper with a piece of bamboo so that the morays cannot get out. These buhi-an are made to order and the larger bubi-an can be sold for 300 pesos.

\section{The Technique and Ecology of Moray Trapping}

\section{Use of the trapping grounds}

Moray eel trapping is conducted all around the Cordova coastal region, which is blessed with massive coral reefs, as well as around neighboring Gilutongan Island and other peripheral islands.

Trapping grounds are chosen in the intertidal flatlands that have a sandy bottom and are packed with lusay (probably a species similar to Enhalus acoroides) sea grass. The sea grass bed provides a hiding place for the organisms that are prey taxa for the moray eel. Morays are nocturnal and feed at shallow depths at night. Moray trap fishing is a method that takes advantage of these feeding behavioural traits.

Moray eel fishing is conducted during low tide, since during any low tide, irrespective of the season or time of day, the morays can be successfully caught. At this study site, fishing is usually conducted in the mornings, but Rau also reported that a time closer to sunset is sometimes preferred and that fishing is not good in November (Rau 1979). In the 2005 study, moray trapping was conducted even during the unstable rainy season as well as during thunderstorms, confirming that one can successfully harvest morays even under poor weather conditions. However, trapping was not conducted during strong winds (Tsuji 2007b). 


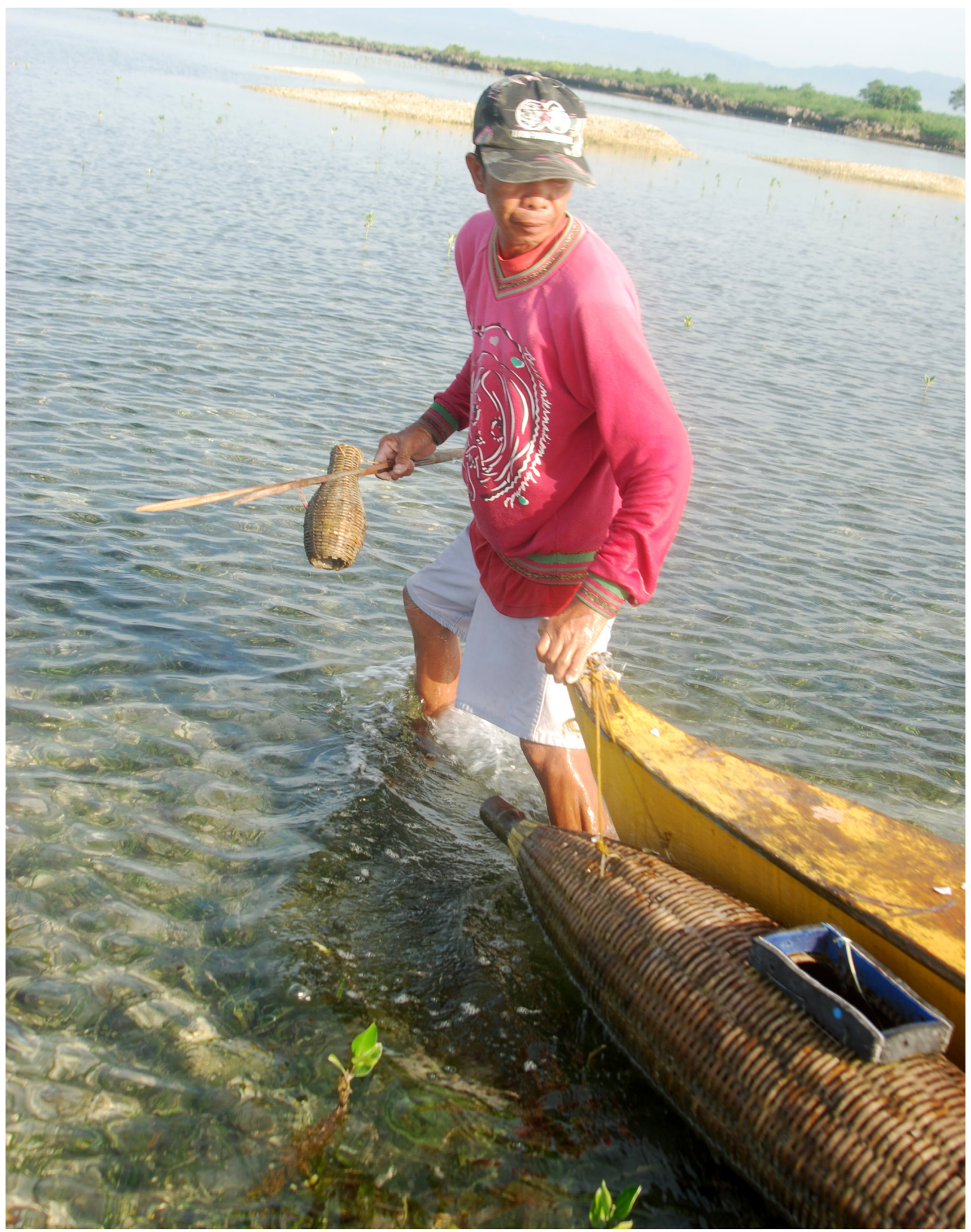

Figure 5. Moray trap fishing.

Source: Photo by the author.

Boats that use a bamboo pole for propulsion are used for trapping in the shallow water if the trapping grounds are close to the shore, whereas a motorboat is used to go out to the surrounding islands that require longer travel time. Both types of vessels are double outrigger boats. Along with the traps, bamboo forks are loaded into the boat, which secure the traps to the trapping grounds. The basket buhi-an and bait are also assembled and loaded into the vessel. In this study, a de-shelled cockle (litub; Anadara antiquata) is used for bait.

During trapping, the boat is pulled with one hand while walking in the shoal water and securing the traps in the trapping grounds with the other hand (Figure 5). While the boat is primarily used 
for transportation, at this juncture it also plays the role of carrying the tools for trapping. In order to set a trap, a $1 \mathrm{~m}$ long pole is created by splitting a 1 metre piece of bamboo. A slit is made into the pole's end into which the loop on the trap is fastened so that the trap will not be washed away by the waves, since the pole is then securely stuck into the sandy bottom. Additionally, due to the fact that during low tide these poles are exposed above the water, they serve as place markers for where the traps were set (Rau 1979; Tsuji 2007b). The traps are set at a few metre intervals apart, but with care so as not to lose sight of them.

At the locations where the traps are set, the bamboo poles protrude above the surface of the water in low tide. By simply walking along the line of poles, the traps can then be harvested. Other than designating the starting and ending points, extra poles can also be stuck in the sand to indicate a change in direction of the trap settings. If the traps cannot be easily relocated, the surrounding landscape may become the basis for finding them.

The traps that have been set are retrieved the next day at low tide and the harvested morays are transferred to buhi-an. Bait is inserted back into the trap and it is set again at a different location.

The characteristics of moray trapping ground usage described below are based on information gleaned from one fisherman's use of the trapping grounds captured with a GPS over the course of three days, beginning on 28 May and ending on 31 May 2008. This fisherman used a nonmotorised boat for moray trapping. The GPS analysis showed that the trapping grounds are sought around the shoals of Cordova without moving long distances between trapping grounds (Figure 6).

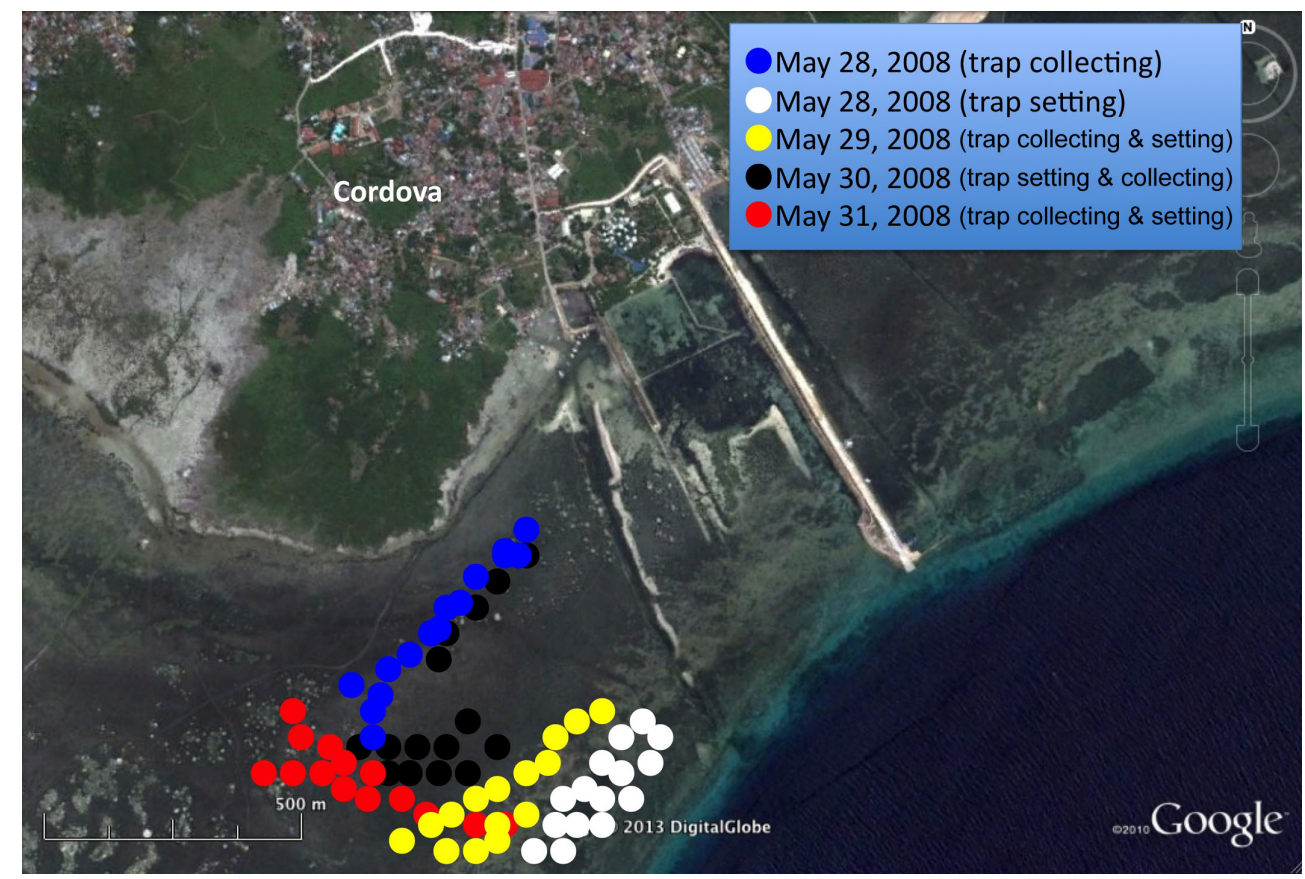

Figure 6. Moray trap setting and collection points.

Source: Drawn by the author, based on Google Map.

Several reasons can be given as to why trapping grounds are not sought over an expansive area. First, the tide dependency method requires that the trap setting and harvesting are done during low tide and completed before the tide rises too high. Thus, if trapping grounds are sought over an expansive area, the prepared traps cannot be harvested or set within the given timeframe. Furthermore, the stamina and economic condition of the individual fisherman may be contributing factors. 


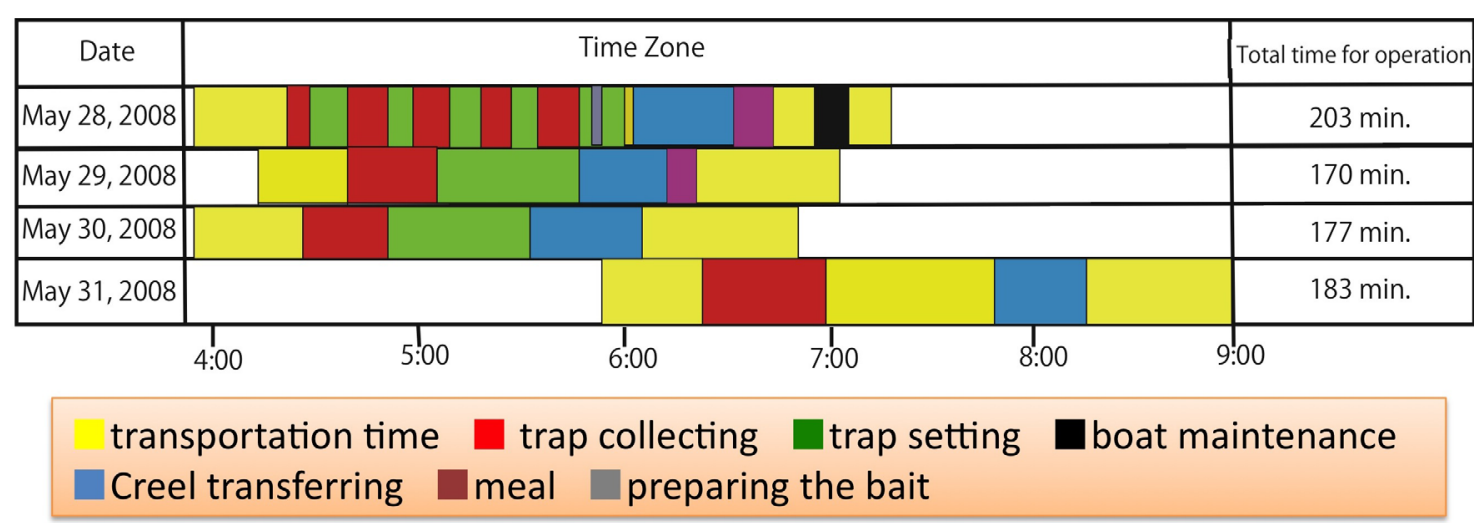

Figure 7. Time allocation for moray trap fishing.

Source: Chart by the author.

In this study, the targeted fisherman was 58 years old, and it is likely that to seek out trapping grounds over a wide area while operating speedily would take a toll on his stamina. If trapping grounds are sought nearby, the time and energy spent on moving is conserved. Furthermore, a rod or a scull is needed for non-motorised boats, which would require a great expenditure of time and energy.

Finally, the fact that trapping grounds are not sought over a wide area indicates that the moray supply is sufficiently rich to meet local demands. However, the shoals of the coastal regions also undergo other types of activities involving harvesting and collection of a variety of fish. Many of these fishing grounds overlap, potentially exposing these locations to population pressure. Thus, it is hard to say conclusively whether or not the location contains a plentiful supply of fish.

\section{Time allocation}

Moray trap fishing is a method that is strongly influenced by the tide. As a result of the fact that a boat is used during the fishing process, the trapping has to be initiated and completed during a time that is suitable for boat travel. Additionally, the harvesting and setting of traps must be conducted during low tide. The moray fish trapping times as well as the time allocation of the tasks involved are described in detail below, based on the results from the on-board study conducted using the individual tracing method.

According to Rau (1979) the time spent moray trap fishing is approximately 3 hours. As a result of the on-board study conducted from 28 through 31 May 2008, the work hours of a single fisherman using a non-motorised boat were $203 \mathrm{~min} ., 170 \mathrm{~min} ., 177 \mathrm{~min}$. , and $183 \mathrm{~min}$., respectively, for each day, averaging 183.25 minutes ( 3 hours and 5 minutes) (Figure 7 ). These on-board study results roughly support the report by Rau (1979). As for the time of day the work was conducted, Rau (1979) stated that the evenings were more desirable, but the author found that in this study, moray eel trapping was conducted in the mornings. Fishing proceeded from just before 4:00 a.m. to around 9:00 a.m. During the 3 days in which this study spanned, 28 to 30 May, the fisherman went out to fish and returned between 6:40 a.m. and 7:20 a.m. On 31 May, the tide was high and the fisherman left to go fishing around 5:30 a.m. and returned around 9:00 a.m.

The workload was distributed to include: 1) transportation on land or sea, 2) setting the traps, 3) harvesting the traps, 4) transferring the morays to the bubi-an, 5) eating, 6) preparing the bait, and 7) maintenance of the boat. The aspect of the work that required the most time was transportation, requiring 36\% (65.97 minutes) of the workload. Next was setting the traps, at 
24\% (43.98 minutes); harvesting the traps, at 19\% (34.82 minutes); transferring the morays to the buhi-an, at 16\% (29.32 minutes); eating, at 3\% (5.5 minutes); and 1\% (1.83 minutes) for both preparing the bait and boat maintenance. It is probably valid to say that $95 \%$ of moray trap fishing is taken up by transportation, setting and harvesting traps, and transferring the morays to the bubi-an.

Concerning the transferring of the harvested morays into the bubi-an, there are fishermen that wait until all of the traps have been collected to transfer them, and also those that transfer the moray into the bubi-an each time a trap is collected. Consequetly, it is possible that the time expenditure may vary greatly between individual fishermen. I would also like to point out that time expenditure for various tasks might also vary according to the number of traps that are set, the locations of the trapping grounds, and individual fishing techniques.

Above, I discussed the allocation of time required for the tasks involved in moray trap fishing when using a non-motorised boat. However, it is estimated that the work hours would be longer for a motorised boat, as the fisherman would cover trapping grounds over a broader area. Below, I present the time allocation of tasks in the case of two other individuals based on information obtained from the moray trap fishing study conducted on 31 July 2005, while recognising that this is a very limited sample.

The fisherman that offered to cooperate in the on-board study using a motorised boat was a 25 -year-old moray trap fisherman, who set out to fish in the direction of Caohagan Island. The fisherman set out at 7:04 a.m. and returned at 2:44 p.m. Including the time to prepare the bait, the total time required for the operation was 489 minutes ( 8 hours, $9 \mathrm{~min}$.). The time this fisherman spent on each task is broken down as follows: 1) land and sea transportation, $42 \%$ (205 min.); 2) time spent resting, 19\% (92 min.); 3) harvesting the traps, $15 \%$ (72 min.); 4) setting the traps (including transferring the morays to the buhi-an), 10\% (47 min.); 5) mealtime, $8 \%$ (39 min.); and 6) preparing the bait, 7\% (34 min.). The transportation time required 205 minutes, but this was partially due to a thunderstorm on the return trip, causing visibility to be cut off by haze. The length of time spent resting was extended due to the fisherman visiting his family members on Caohagan Island before starting work.

Two hundred and five (205) minutes were required for transportation by the motorised boat operator in his trap fishing activities to and from his original destination, almost tripling the time used compared to the non-motorised boat operator's time of 65.97 minutes. There is almost no difference in the time expended for setting and harvesting the traps: 43.98 minutes versus 47 minutes. In harvesting of the traps (including the time required for transferring the morays into the buhi-an), the non-motorised boat operator expended 64.14 minutes and the motorised boat operator expended 72 minutes, showing an 8-minute difference.

However, the non-motorised boat operator averaged 96 traps set and harvested, whereas the latter set and harvested 120. Hypothetically, if the non-motorised boat operator had set 120 traps, the time expended setting them would be 55 minutes and 80 minute for harvesting them. It can be concluded that the motorised boat moray trap fisherman works more efficiently. The differences in theses results could reflect age differences, and the fact that by operating at a further distance with a motorised boat, one may have to be more conscious of the tide.

Moray trap fishing in nearby areas using a non-motorised boat can be conducted at a more relaxed pace. However, one is forced to compete with the other moray trap fishing businesses for both the supply and the fishing grounds, while continuing to operate under the disturbing conditions of the population pressure on the fishing grounds. On the other hand, with the motorised boat, it is possible to seek trapping grounds in areas where there is almost no moray trap fishing being 
conducted and a greater fish harvest can be anticipated. However, more financial expenditures and physical effort is required for the fuel to commute out to the trapping grounds, time for the commute, and for a faster operating pace, while remaining conscious of the shifting tide.

Above I have attempted to study and analyse the distribution of time allotted for each work task and the total work hours for moray trap fishing. I found that the work is being carried out at about the same tempo as Rau (1979) reported in 1970. Furthermore, I have found that moray trap fishing is being conducted with the use of motorised boats, leading to a significant increase in transportation time for moray fishing as well as a trend toward operating at an accelerated pace. From these facts, along with the changes in the shoreline environment and the moray boom, it can be implied that moray trap fishing is in a transitional period of change.

\section{Productivity of moray traps}

Generally speaking, fishing tools and fishing techniques have been refined throughout the years according to the behaviour of the fish, the environmental characteristics of the fishing grounds, and the choice of fish targeted for harvest. It is thought that the wisdom of the local fishing populace is reflected in the tools and the fishing techniques. For example, let us look at the three main types of traps that were used at the study sites. Pieces of fish are used as bait in the hemi-spherical panggal trap, which are attached to coral about $5 \mathrm{~m}$ below the surface. With these traps, wrasse and mottled spinefoot are caught. The square trap called a teming is set in the coral shallows of sand or sea grass at about $1 \mathrm{~m}$ below the surface and is used to catch non-palatable crabs of the box crab or spider crab families, ibis (cardinal fish family) or kasag (swimming crab) and other small fish. De-shelled cockle (litub; Anadara antiquata) are used as bait in the bantak trap, which are set in the same environment as the teming, to catch smaller morays. Each trap choice, the shape of the trap, the bait used, the environment in which it is set, and the targeted harvest is considered. Moreover, fishermen are engaged in the type of fishing that is suited to their needs and specialty skills.

The tools of the trade and techniques have been honed by trial and error over many years. The moray trap, bantak, has evolved into a jar or a Japanese sake bottle shape, used almost exclusively to catch bakasi.

Below, I discuss the productivity of the moray trap with reference to harvest data from moray trap fishing gleaned during the study period. During the 2008 study, 384 traps were used over a period of 4 days and 907 morays were caught. The combined weight of the morays is $18,295 \mathrm{~g}$ (Table 1), resulting in an average harvest per day of approximately $4.57 \mathrm{~kg}$, or 226 moray caught with 96 traps. A range of one to eight morays were captured in 1 trap (an average of 2.4 morays).

Table 1. Moray Trap Fishing Yield Volume.

\begin{tabular}{lllll}
\hline Date & No. of traps () ... No. catch & No. of Moray & Weight (g) & Income (Pesos) \\
\hline May 28, 2008 & $96(23)$ & 184 & 3,565 & 300 \\
May 29, 2008 & $95(17)$ & 237 & 4,860 & 480 \\
May 30, 2008 & $87(11)$ & 253 & 5,195 & 500 \\
May 31, 2008 & $106(25)$ & 233 & 4,675 & $?$ \\
Total & $384(76)$ & 907 & 18,295 & 1,280 \\
Average & $96(19)$ & 226.75 & $4,573.75$ & 426.67 \\
\hline
\end{tabular}

Source: Table by the author. 
Out of the 384 traps, there were 77 traps in which no moray eels were caught. Consequently, $80 \%$ of the traps were productive. In the 2005 study, 115 out of 120 traps $(95.8 \%)$ yielded at least one moray with a range of 1 to 5 morays captured in a single trap. These numbers reflect the raw data from only 2 fishermen over a period of five days. Without taking into consideration the fisherman's skill level, the difference in the conditions and environment of the fishing grounds, and the seasonal difference, a meaningful discussion on the productivity may not be entirely accurate.

Although interpretation of this information is an issue to be taken up in future studies, it is noteworthy to discuss particular episodes, which may show that the fisherman's ecological knowledge or skill level based on their experience might hold the key to the productivity of the yield. First, during the 2005 study, an area was discovered in which no morays were found in a consecutive number of traps. Again, during the 2008 study when a fisherman, who had just recently become a moray trap fisherman, set a homemade, ill-shaped trap, instead of bakasi morays, the trap yielded snowflake morays, which have almost no market value. These episodes could be mere coincidences, but are noteworthy because they could lead to an understanding of moray trap fishing in terms of the fisherman's ecological knowledge and technical skills based on experience.

Next, the productivity of moray trap fishing from the standpoint of profitability is considered. During the 2008 study, the sales volume of the morays was recorded for 3 of the 4-days surveyed. Sales volumes of 300 pesos, 480 pesos, and 500 pesos, respectively, for each day were recorded, averaging 426 pesos per day of work. During the 2005 study, data on sales volume and moray yields was obtained by means of a paper survey administered to moray fishermen over a 21-day period. The results demonstrate that morays were harvested 17 out of 20 days for an average of 6.4 caltex (the smallest was 3 caltex with the greatest being 10 caltex). The average sales volume was 320 pesos (150 pesos for the lowest volume and 500 pesos for the highest volume). On average, the time spent working was 3 hours (using a non-motorised boat). Considering that at the time of the 2008 study, the legal minimum wage for 1 day in the region of the study site was 185 to 200 pesos, moray fishing is a rather profitable occupation.

In the future, there will likely be a demand for comparative studies including the individual differences between fishermen, differences in socio-economic conditions, and income and labour effectiveness ratios in relationship to other methods of fishing, as well as yield volumes by season, which may affect the fishing business profitability. However, at present, the future of fishing operations in Cordova looks bright due to the area's rich resource of marine morays, a regional demand for morays, and support from local events such as the Moray Festival.

\section{Summary and Conclusion}

I have discussed and analysed the techniques and ecological aspects of moray trap fishing primarily based on the results from an on-board survey of moray trap fishing. The on-board survey was based solely on observations and the recorded activities of two individual fishermen and thus cannot be said to elucidate the comprehensive state of moray fishing in this field survey site. However, one can say that a rough sketch of the characteristics and issues has been adequately highlighted.

First, the moray trap fishing business targets morays for their harvest, but given the structure of the trap, it is clear that the actual targets are smaller morays (bakasi). More specifically, the trap is designed so that smaller moray eels can enter. The moray trap is tightly woven without any spaces in between, suggesting that this is done intentionally so that a long thin small moray may be able to escape. However, the purpose of tightly weaving the trap may be to reproduce more closely the 
preferred environment of the moray by creating a dark location within the trap. This supports the idea that the moray trap-making technology stems from an awareness of moray ecology and a grasp of design technology that prevents the catch from escaping.

Second, in terms of selecting the trapping grounds, it appears that moray trap fishermen choose them randomly. During the study, it was confirmed that morays enter most of the traps. However, small stretches of trapping grounds where morays did not enter the traps, as well as trapping grounds where other types of morays other than the targeted type entered the traps were also found. It is conceivable that a strong contributing factor to the fisherman's technique of selecting and using trapping grounds is a reflection of his experience and ecological knowledge of the moray routes and behavioural characteristics. However, at this time we do not have sufficient data to explain these factors. These are topics for consideration in future studies.

As for the allocation of time spent on various tasks for moray trap fishing, operations are greatly affected by the tide, requiring the fisherman to fish with a constant eye on the tide. Additionally, the number of traps used is determined by the fisherman's physical endurance in relation to his ability to complete an operation within the timeframe of a tide-change as well as the fisherman's socio-economic condition. Under such restrictive conditions, a fisherman must utilise his labour capacity, skill, experience, and knowledge of the ecology to set traps within the appropriate location and timeframe when it is probable that a moray will enter the trap.

Future studies that work towards unraveling the fishermen's experience-based techniques and ecological knowledge should focus on documenting more details about fishermen's usage strategies for their trapping grounds and their allotment of time spent on various tasks.

Today, moray trap fishing is in flux. While continuing to maintain the static aspects described above, it is being carried out under dynamic environmental conditions. The moray trapping grounds are being exposed to danger from land development, dynamite fishing, and population growth, as well as overlapping operational activities from other fishing businesses. They have experienced hardship from incidences where the trapped morays or the morays in the fisherman's buhi-an have been stolen. The results from this field survey, and based on information about the yield ratios from neighbouring regions, the trapping grounds at the survey site were productive. However, keeping in mind that each individual fisherman's situation varies, a large problem remains in the possibility that the results from this study only disclose specific fishing activities conducted under favourable conditions by particular fishermen who happen to fish wisely.

Neighbouring regions are using motorised fishing boats to fish in areas further offshore. This may be due to the fact that the moray resources are not at satisfactory levels, or perhaps fishermen are seeking safe and more productive trapping grounds. In a simple comparison of the incomes from the moray fishermen who used motorised and non-motorised boats in this study, it was found that the fisherman using a non-motorised boat in close vicinity earned a higher income.

However, it is possible that there is a significant difference in these fishermen's knowledge of fishing ground ecology and usage skills, given that the more productive fisherman's age is more than double that of the less productive fisherman. Perhaps trapping grounds at further distances offer a more stable yield even with poorer fishing skills and knowledge. In terms of allocation of time allotted to operation tasks, the difference between the two fishermen was almost double. It should also be pointed out that the expense of gasoline and the additional labour effort required to complete operations while being further limited by the tide change should be factored into the price of seeking distant trapping grounds with motorised boats. 
While facing such contemporary challenges head-on, fishermen have high hopes and expectations for future moray fishing and the continued supply of moray at this site. Praising the rich marine supply of moray, the government started the Moray Festival and its promotional policies are producing events that spotlight the importance of this resource.

However, to date, explicit management of the supply of morays has never been conducted. Instead, the residents have a blind sense of expectation of the continuation of their rich moray marine resource. The marine moray supply has been maintained thus far because the moray trap fishing business is controlled not only by the tides, but also by physical and socio-economic constraints such as the fishermen's limited economic resources available to procure a boat and moray traps. In the future, studies need to focus on how the local moray promotional policies affect future tourism and the economy. Other important issues include how the moray trap fishing operations will evolve as a result of the increase in moray demand and heightened expectations, and how these factors will affect the livelihood of the fisherman, the marine supply, the value of morays, and the ecological environment.

\section{References}

Ator, L.A. 2007. Municipality of Cordova, Cebu Brief Profile. Unpublished manuscript. Cebu: Municipality of Cordova.

Balogo, O.G. 1996. Bamboocraft: The Guimbaleños Fishing Traps and Gears. In Center for West Visayan Studies. Proceedings of the 6th Conference on West Visayan History and Culture, pp. 16-22. Iloilo City: University of the Philippines-Visayas.

Cadeliña, R.V., J.V. Perez, and R.V. Mascuñana. 1986. Artifacts from the Visayan Communities: A Study of Extinct and Extant Culture. Dumaguete: Silliman University.

Calderon-Hayhow, et al. 1994. Appendix: Fishing Material Culture of Fishermen in Barrio Ajong, Sibulan, Negros Oriental. In I. Ushijima and C.N. Zayas (eds), Fishers of the Visayas: Visayas Maritime Anthropological Studies I: 1991-1993, pp. 393-464. Quezon City: CSSP Publications.

Cebu Pagasa Complex. 2005. Cebu PAGASA Complex Climatological Normalstremes (1973-2004) 32 year Period. Unpublished maunscript.

Coast and Geodetic Survey Department. 2005. Tide and Current Tables: Philippines 2005. Makati City: Coast and Geodetic Survey Department.

Garcia, J.R. 2003. Epektib Gyud. The Freeman 13 July.

Green, S.J., J.O. Flores, J.Q. Dizon-Corrales, R.T. Martinez, D.R. Nuñal, N.B. Armada and A.T. White. 2004. The Fisheries of Central Visayas, Philippines: Status and Trends. Coastal Resource Management Project of the Department of Environment and Natural Resources and the Bureau of Fisheries and Aquatic Resources of the Department of Agriculture. Cebu City: Department of Agriculture.

Hutchins, M., D.A. Thoney, P.V. Loiselle, and N. Schlager (eds). 2003. Grzimek's Animal Life Encyclopedia (2nd Edition). Farmington Hills: Gale Group.

Luchavez, J.A. and B.T. Abrenica. 1997. Fisheries Profile of Bais Bay, Negros Oriental. Silliman Journal 37(3-4):93-171.

Municipality of Cordova. 2004. Comprehensive Municipal Profile: Including Plans, Programs, and Accomplishments. Cebu: Municipality of Cordova.

Rau, N. 1979. Small-Scale Fishing Methods Used around Cebu City, Philippines. The Philippine Scientist $16: 1-27$. 
San Carlos Publications and Office of Population Studies of San Carlos. 2004. Cebu: A Demographic and Socioeconomic Profile Based on the 2000 Census. Cebu: San Carlos Publications and Office of Population Studies of San Carlos.

Schoppe, S., J. Gatus, P.P. Milan and R. Seronay. 1998. Gleaning Activities on the Islands of Apid, Digyo and Mahaba, Inopacan, Leyte, Philippines. The Philippines Scientist 35:130-140.

Sollano, J.P. 2005. Cordova Town to Launch "Bakasi” Fest Aug. 14. The Freeman 21 July.

Suda, K. 1994. Methods and Problems in Time Allocation Studies. Journal of Anthropological Science 102:13-22.

Szanton, D. 1971. Estancia in Transition. Quezon City: Ateneo de Manila University Press.

Tawa, M. 1981. The Fishing Business in Sapian, Panay Island, Capiz: The Fishing Tools and Fishing Methods of Coastal Fishing in Sapian, the Northern Region of Panay Island. In the compilation of the Hiroshima Shudo University compilation of Philippine Study Projects (eds), A Comparative Study of Japan and Philippines Inland Sea Regions Focusing on Hiroshima Prefecture and Panay Island, pp. 52-63. Hiroshima: Hiroshima Shudo University Research Institute. (in Japanese).

Tawa, M. 2006. People who Fish in Southeast Asia. Tokyo: Nakanishi Publishing. (in Japanese).

Tsuji, T. 2007a. Coastal Gleaning and Resource Utilization of Sipunculus robustus and Dolabella auricularia in Mactan Island, Philippines. Tropical Ecology Letters 68:6-12. (in Japanese).

Tsuji, T. 2007b. A Note about Moray Fishing Activity in Mactan Island, Cebu, Philippines. Humanities and Sciences 22:141-151. (in Japanese).

Umali, A.F. 1950. Guide to the Classification of Fishing Gear in the Philippines. Washington: United States Government Printing Office.

Yano, T. 1994. The Characteristics of Fisherfolk Culture in Panay: From the Viewpoint of Fishing Ground Exploitation. In I. Ushijima and C.N. Zayas (eds.), Fishers of the Visayas: Visayas Maritime Anthropological StudiesI: 1991-1993, pp. 3-51. Quezon City: CSSP Publications.

Yano, T. and T. Kobayashi. 1994. Continuity and Change to the Manughudhod. In I. Ushijima and C.N. Zayas (eds), Fishers of the Visayas: Visayas Maritime Anthropological StudiesI: 1991-1993, pp. 163- 177. Quezon City: CSSP Publications.

Zayas, C.N. 1994. Pangayaw and Tumandok in the Maritime World of the Visayan Islanders. In I. Ushijima and C.N. Zayas (eds), Fishers of the Visayas: Visayas Maritime Anthropological Studies I: 1991-1993, pp. 75-131. Quezon City: CSSP Publications.

Zayas, C.N. 2004. Atob and Bato: Two Sides of Philippine Lithic Heritage. Pilipinas 43:55-70. 